\title{
The importance of the nuclear positioning of the PPARG gene for its expression during porcine in vitro adipogenesis
}

\author{
Joanna Stachecka • Joanna Nowacka-Woszuk • \\ Pawel A. Kolodziejski • Izabela Szczerbal 1 (D)
}

Received: 27 September 2018 / Revised: 4 January 2019 / Accepted: 9 January 2019 /Published online: 17 January 2019

(C) The Author(s) 2019

\begin{abstract}
Proper expression of the $P P A R G$ gene, which encodes a key transcription factor of adipogenesis, is indispensable in the formation of mature adipocytes. The positioning of a gene within the nuclear space has been implicated in gene regulation. We here report on the significance of the PPARG gene's nuclear positioning for its activity during in vitro adipogenesis in the pig. We used an established system of differentiation of mesenchymal stem cells derived from bone marrow and adipose tissue into adipocytes. The differentiation process was carried out for 7 days, and the cells were examined using the 3D DNA/immuno-FISH and RNA/ DNA-FISH approaches. PPARG transcript level was measured using real-time PCR, and PPAR $\gamma$ activity was detected with colorimetric assay. Changes in the nuclear location of the PPARG gene were observed when we compared undifferentiated mesenchymal stem cells with mature adipocytes. The gene moved from the nuclear periphery to the nuclear center as its transcriptional activity increased. The RNA/DNA-FISH
\end{abstract}

Responsible Editor: Irina Solovei

Electronic supplementary material The online version of this article (https://doi.org/10.1007/s10577-019-09604-2) contains supplementary material, which is available to authorized users.

J. Stachecka · J. Nowacka-Woszuk · I. Szczerbal $(\bowtie)$

Department of Genetics and Animal Breeding, Poznan University of Life Sciences, Wolynska 33, 60-637 Poznan, Poland e-mail: izabel@up.poznan.pl

P. A. Kolodziejski

Department of Animal Physiology and Biochemistry, Poznan University of Life Sciences, Wolynska 35, 60-637 Poznan, Poland approach shows that differences in primary transcript production correlated with the allele's nuclear positioning. Transcriptionally active alleles preferentially occupy the central part of the nucleus, while inactive alleles are found on the nuclear periphery. We also show that transcription of PPARG begins with one allele, but that both alleles are active in later stages of differentiation. Our results provide evidence that functionally distinct alleles of the PPARG gene are positioned in different parts of the cell nucleus. This confirms the importance of nuclear architecture to the regulation of PPARG gene transcription, and thus to the fate of the adipose cell.

Keywords Adipocytes $\cdot$ Allele $\cdot$ Mesenchymal stem cells $\cdot$ Nuclear architecture $\cdot$ Pig $\cdot$ RNA-FISH

\begin{tabular}{|c|c|}
\hline \multicolumn{2}{|c|}{ Abbreviations } \\
\hline $3 \mathrm{D}$ & three-dimensional \\
\hline AD-MSC & $\begin{array}{l}\text { adipose-tissue-derived } \\
\text { mesenchymal stem cells }\end{array}$ \\
\hline BM-MSC & $\begin{array}{l}\text { bone-marrow-derived } \\
\text { mesenchymal stem cells }\end{array}$ \\
\hline cDNA & complementary DNA \\
\hline DAPI & 4',6-diamidino-2-phenylindole \\
\hline FISH & fluorescent in situ hybridization. \\
\hline Hem-MSC & $\begin{array}{l}\text { hemangioma-derived } \\
\text { mesenchymal stem cells }\end{array}$ \\
\hline PBS & phosphate buffered saline \\
\hline PFA & paraformaldehyde \\
\hline PPARG & $\begin{array}{l}\text { peroxisome proliferator-activated } \\
\text { receptor gamma }\end{array}$ \\
\hline RT & room temperature \\
\hline
\end{tabular}


RT-PCR reverse transcription polymerase chain reaction

$\mathrm{SSC}$

SSC13 Sus scrofa chromosome 13

\section{Introduction}

Adipogenesis, the formation of fat cells, is regulated by a complex and orchestrated gene expression program (Lowe et al. 2011). A number of positive and negative transcription factors of adipocyte differentiation have been identified (Farmer 2006), and a central role is played among them by peroxisome proliferatoractivated receptor $\gamma(\mathrm{PPAR} \gamma)$, a ligand-activated transcription factor that belongs to the nuclear receptor superfamily. This factor has been recognized as the master regulator of adipogenesis, since no other factor has been discovered to promote this process in the absence of PPAR $\gamma$ (Rosen and MacDougald 2006). Apart from adipocyte differentiation, PPAR $\gamma$ also regulates adipocyte metabolism in mature adipocyte cells and insulin sensitivity (Lehrke and Lazar 2005; Siersbæk et al. 2010). PPAR $\gamma$ is encoded by the PPARG gene, which is highly expressed in adipose tissues, and whose expression increases during adipogenesis (Lee and Ge 2014). PPAR $\gamma$ upregulates genes involved in fatty acid metabolism and triglyceride storage and is consequently involved in maintaining the adipocyte phenotype (Ruschke et al. 2010).

Given the importance of PPAR $\gamma$ in the development of adipose tissue, understanding the molecular mechanisms that regulate its expression is highly important in the context of human obesity and obesity-related disorders (Shao et al. 2016). Adiposity is also of great interest in domestic animals, since proper functioning of the adipose tissue determines animal health, neonatal survival, reproductive ability, postnatal growth, and production efficiency (Louveau et al. 2016; Stachowiak et al. 2016). The transcriptional regulation of PPARG during adipogenesis is well understood, and many positive and negative factors, as well as signaling pathways, have been described (Rosen and MacDougald 2006; Farmer 2006; Mota de Sá et al. 2017). PPARG expression is also controlled by epigenetic mechanisms, including DNA methylation, histone modifications, and chromatin remodeling (Fujiki et al. 2009; Sugii and Evans 2011; Lee and Ge 2014). Apart from these mechanisms, it has been postulated that nuclear organization may play a role in gene regulation (Fraser and Bickmore 2007; Fedorova and Zink 2008). Mammalian genomes are hierarchically organized in the interphase nucleus, starting from the chromosome territories (Cremer and Cremer 2010) and the A (active) and B (inactive) compartments (Lieberman-Aiden et al. 2009), through topologically associating domains (TADs) and smaller sub-TADs (Dixon et al. 2012; Phillips-Cremins et al. 2013), which are stabilized by cohesin and CCCT C-binding factor (CTCF) (Rao et al. 2014; Sanborn et al. 2015). It has been postulated that this higher-order organization of the genome has some functional relevance.

It has been well established that chromosome territories, chromatin domains, and genes occupy preferential locations within the three-dimensional (3D) nuclear space and that their arrangement may affect gene expression (Cremer and Cremer 2010; Ferrai et al. 2010). The positioning of genes toward the nuclear periphery or the nuclear interior, the location of one locus relative to another, and their associations with different nuclear components (such as the chromosome territory, the nuclear envelope, and the nucleolus) and bodies (including nuclear speckles and transcription factories) are related to transcriptional status and can lead to their activation or repression (Meaburn 2016). In three-dimensional nuclear space, the positions of the chromosome territories are correlated with gene density: gene-rich chromosomes are located more centrally, while gene-poor chromosomes are usually located closer to the nuclear periphery (Bolzer et al. 2005). The differential positioning of active and silent genes within the nuclear space has also been observed, with active genes tending to be located in the nuclear interior and inactive genes on the nuclear periphery (Meister et al. 2010). Changes in nuclear organization and nuclear architecture are characteristic of cellular differentiation and development processes, including adipogenesis (Charó et al. 2016; Stachecka et al. 2018). Previous studies on a porcine in vitro model of adipocyte differentiation have shown that key adipogenic genes are repositioned from the nuclear periphery to the nuclear interior without relocation of the chromosome territories (Szczerbal et al. 2009). These gene relocations correspond with transcriptional activity. This also concerns the PPARG gene, located on porcine chromosome 13 (SSC13), which moves from the 
nuclear periphery to the nuclear interior during the differentiation of mesenchymal stem cells (MSC) into adipocytes.

The repositioning of $P P A R G$ during adipogenesis has not been investigated in greater detail on the cellular level. The study described here thus aimed to comprehensively examine the effects of the nuclear positioning of PPARG on its expression. The study was performed on the domestic pig (Sus scrofa), which is not only an important livestock species, but is also used as a model organism for human diseases, including obesity. We compared two in vitro adipogenic differentiation systems derived from porcine mesenchymal stem cells isolated from bone marrow (BM-MSC) and adipose tissue (AD-MSC). Using both cellular methods (3D DNA/immuno-FISH and DNA/RNA-FISH) and molecular methods (real-time PCR and colorimetric assay), we evaluated how the nuclear positioning of PPARG gene alleles affects their expression over subsequent days of adipogenesis.

\section{Materials and methods}

\section{Cell culture}

Porcine mesenchymal stem cells were isolated from adipose tissue and bone marrow from a 3-month-old Polish Large White pig, as described by Kociucka et al. (2016). The cells were cultured in advanced DMEM medium (Gibco) supplemented with 10\% FBS (Sigma-Aldrich), 5 ng/ml FGF-2 (PromoKine), $2 \mathrm{mM}$ L-Glutamine (PAA), $1 \mathrm{mM}$ 2-mercaptoethanol (Sigma-Aldrich), $1 \times$ antibiotic antimycotic solution (Sigma Aldrich), and MEM NEAA (Thermo Fisher Scientific) at $37{ }^{\circ} \mathrm{C}$ with $5 \% \mathrm{CO}_{2}$ supplementation. To induce adipogenic differentiation, the cells were grown to confluency and were cultured with adipogenic differentiation medium composed of advanced DMEM (Gibco) with $10 \%(v / v)$ FBS (Sigma), $1 \times$ antibiotic antimycotic solution (Sigma Aldrich), MEM NEAA (Thermo Fisher), 5 ng FGF-2 (PromoKine), $1 \times$ linoleic acid albumin (Sigma-Aldrich), $1 \times$ ITS (Sigma-Aldrich), $1 \mu \mathrm{M}$ dexamethasone (Sigma-Aldrich), $100 \mu \mathrm{M}$ indomethacin (Sigma-Aldrich), and $50 \mathrm{mM}$ IBMX (Sigma-Aldrich). The differentiation process was allowed to proceed for 7 days and lipid droplet formation was examined using a phase-contrast microscope (TS100 Eclipse, Nikon).
Oil Red O staining

Lipid accumulation was monitored with the use of Oil Red O staining. Briefly, cells were fixed with $4 \%$ paraformaldehyde in PBS $(w / v)$ for $15 \mathrm{~min}$ at room temperature (RT). The cells were then rinsed with double distilled water and incubated with $0.3 \%$ Oil Red O (Sigma-Aldrich) solution in 2-propanol diluted in water $(3: 2 v / v)$ at RT for $1 \mathrm{~h}$. After extensive rinsing with double-distilled water, the cells were left in PBS and examined using a phase-contrast microscope (TS100 Eclipse, Nikon).

\section{Real-time PCR}

Total RNA was isolated from cells on each day of differentiation using TriPure Isolation Reagent (Roche Diagnostic), following the manufacturer's instructions. The concentration and purity of the RNA samples were determined using a NanoDrop spectrophotometer (Thermo Scientific). A Transcriptor High Fidelity cDNA Synthesis Kit (Roche Diagnostic) was used to reverse transcribe $2 \mu \mathrm{g}$ RNA. The PPARG transcript level was conducted using a LightCycler 480 SYBR Green I Master kit (Roche Diagnostic) on a LightCycler 480 II (Roche Life Science). The analysis was performed in duplicate for each sample. Relative transcript quantification was carried out using the 2- $\Delta \Delta \mathrm{CT}$ method (Livak and Schmittgen 2001) with undifferentiated cells (day 0) as a calibrator. The ribosomal protein L27 (RPL27) gene was used as a reference gene. The primer sequences are provided in Supplementary Table 1.

Protein analysis

Nuclear protein extraction was performed using a $\mathrm{Nu}-$ clear Extraction Kit (Abcam), following the manufacturer's instructions. Nuclear extracts were collected on each day of adipogenesis. Protein concentration was measured with a Qubit Protein Assay Kit (Thermo Fisher Scientific) on a Qubit 2.0 Fluorometer (Invitrogen). PPAR $\gamma$ DNA-binding affinity was assessed using a PPAR $\gamma$ transcription factor assay kit (Abcam). The experiment was performed twice-initially in duplicate and then in triplicate. The protein concentrations were equalized and $10 \mu \mathrm{l}$ of nuclear extract was added to the wells, coated with a specific DNA sequence containing the peroxisome proliferator response element, and incubated overnight at $4{ }^{\circ} \mathrm{C}$. Washing, incubation with 
antibodies (primary polyclonal anti-PPAR $\gamma$ antibody and goat anti-rabbit HRP conjugate secondary antibody), and color development procedures were performed in line with the manufacturer's protocol. The absorbance was read at $450 \mathrm{~nm}$ using a Synergy 2 device (Biotek).

\section{Hybridization probe}

A probe for detecting the PPARG gene was derived from the PigE BAC library (Anderson et al. 2000) (http://www.arkgenomics.org/clonesVectors/). The BAC clone (PigE-86P19) was selected to span only the sequence of the gene of interest. DNA from the BAC clone was isolated by alkaline lysis and labeled by the random-priming method with biotin-16-dUTP (Roche Diagnostic) or digoxigenin-11-dUTP (Roche Diagnostic) using a BioPrimer Array CGH genomic labeling system (Thermo Fisher Scientific). The specificity of the probe was verified by PCR using specific primers (Suppl. Table 1) and 2D fluorescence in situ hybridization (2D-FISH) on metaphase chromosomes (Suppl. Fig. 1). Slides were analyzed under a Nikon E600 Eclipse fluorescence microscope.

\section{D DNA/immuno-FISH}

Detection of DNA target and nuclear protein was performed in line with the protocol described by Solovei and Cremer (2010), with slight modifications. Cells were grown directly on glass slides. Cells from each day of adipocyte differentiation were fixed in $4 \%$ paraformaldehyde in PBS $(w / v)$ for $10 \mathrm{~min}$. The 3D preserved cells were then incubated in $20 \%$ glycerol in PBS $(v / v)$ and exposed to seven repeated freeze-thaw cycles in liquid nitrogen. The cells were treated with $0.1 \mathrm{M} \mathrm{HCl}$ for $5 \mathrm{~min}$ and equilibrated in $50 \%$ formamide in $2 \times$ $\mathrm{SSC}$. The probe was denatured at $70^{\circ} \mathrm{C}$ for $10 \mathrm{~min}$ and preannealed at $37{ }^{\circ} \mathrm{C}$ for $10 \mathrm{~min}$. The nuclei were denatured at $75{ }^{\circ} \mathrm{C}$ in $70 \%$ formamide in $2 \times \mathrm{SSC}$ for $3 \mathrm{~min}$ and in $50 \%$ formamide in $2 \times \mathrm{SSC}$ for $1 \mathrm{~min}$. Hybridization was performed in a humid chamber at $37^{\circ} \mathrm{C}$ for 2 days. After hybridization, the slides were washed three times in $50 \%$ formamide in $2 \times \mathrm{SSC}$ for $6 \mathrm{~min}$ and three times in $2 \times \mathrm{SSC}$ for $6 \mathrm{~min}$ at $42^{\circ} \mathrm{C}$. The slides were equilibrated in $4 \times \mathrm{SSC} / 0.05 \%$ Tween- 20 , and then blocked with $3 \% \mathrm{BSA}$ in $4 \times \mathrm{SSC} / 0.05 \%$ Tween-20 for $30 \mathrm{~min}$ at RT. Detection was performed using antidigoxigenin-fluorescein Fab fragments
(Roche Diagnostic) at a dilution of 1:100. The slides were washed three times in $4 \times \mathrm{SSC} / 0.05 \%$ for $6 \mathrm{~min}$ at $42{ }^{\circ} \mathrm{C}$ and 3 times for $5 \mathrm{~min}$ in PBS at RT. In the next step, cells were subjected to immunostaining. Primary antibody against lamin $\mathrm{A} / \mathrm{C}$ (monoclonal anti-lamin $\mathrm{A} /$ $\mathrm{C}$ produced in mouse, Sigma-Aldrich) was applied on slides at a dilution of 1:100 and incubated overnight at $4{ }^{\circ} \mathrm{C}$. The slides were then washed three times in PBS and incubated with secondary antibody (anti-mouse IgG (whole molecule)-TRITC antibody produced in rabbit, Sigma-Aldrich) diluted 1:200 for $1 \mathrm{~h}$ at RT. This was followed by three washes in PBS for $5 \mathrm{~min}$. The nuclei were counterstained with DAPI in Vectashield mounting medium (Vector Laboratories).

\section{D RNA/DNA-FISH}

Sequential RNA and DNA detection by FISH was performed in line with the protocol described by Brown and Buckle (2010), with slight modifications. For this procedure, all buffers were prepared using DEPC-treated water. Cells growing directly on coverslips were fixed in $4 \%$ formaldehyde and 5\% glacial acetic acid in $1 \times$ saline for $20 \mathrm{~min}$ and washed three times in PBS ( $w /$ $v$ ). The coverslips were stored in $70 \% \mathrm{EtOH}$ at $-20{ }^{\circ} \mathrm{C}$. Before hybridization, the slides were equilibrated in Tris/saline solution and permeabilized with $0.02 \%$ pep$\sin$ solution for $4 \mathrm{~min}$ at $37^{\circ} \mathrm{C}$. The coverslips were then washed in DEPC-treated water, fixed in $3.7 \%$ formaldehyde solution for $4 \mathrm{~min}$, and washed with PBS $(w / v)$, before being dehydrated with $70 \% \mathrm{EtOH}, 90 \% \mathrm{EtOH}$, $100 \% \mathrm{EtOH}$, and air-dried. The probe was denatured at $90{ }^{\circ} \mathrm{C}$ for $8 \mathrm{~min}$ and preannealed at $37^{\circ} \mathrm{C}$ for $10 \mathrm{~min}$. Hybridization was performed overnight in a humid chamber at $37{ }^{\circ} \mathrm{C}$, after which the coverslips were washed three times with $2 \times \mathrm{SSC}$, followed by two washes in Tris/saline/Tween-20 solution. Then, cells were blocked in $1.35 \%$ blocking solution (ELISA blocking reagent, Roche Diagnostic) for $30 \mathrm{~min}$ at RT. Detection was performed using Cy3-Streptavidin (GE HealthCare) diluted 1:200. The cells were then fixed in $3.7 \%$ formaldehyde solution for $4 \mathrm{~min}$ and washed with PBS $(w / v)$. DNA hybridization was performed directly after RNA detection. The nuclei were denatured at $75^{\circ} \mathrm{C}$ in $70 \%$ formamide in $2 \times \mathrm{SSC}$ for $3 \mathrm{~min}$ and in $50 \%$ formamide in $2 \times \mathrm{SSC}$ for $1 \mathrm{~min}$. The probe was denatured at $70{ }^{\circ} \mathrm{C}$ for $10 \mathrm{~min}$ and preannealed at $37^{\circ} \mathrm{C}$ for $10 \mathrm{~min}$. Hybridization was performed in a humid chamber at $37{ }^{\circ} \mathrm{C}$ for 2 days. After hybridization, the 
coverslips were washed three times in $50 \%$ formamide in $2 \times \mathrm{SSC}$ for $6 \mathrm{~min}$ at $42^{\circ} \mathrm{C}$ and three times in $2 \times \mathrm{SSC}$ for $6 \mathrm{~min}$ at $42{ }^{\circ} \mathrm{C}$. The coverslips were equilibrated in $4 \times \mathrm{SSC} / 0.1 \%$ Tween- 20 and blocked with $3 \%$ BSA in $4 \times \mathrm{SSC} / 0.05 \%$ Tween- 20 for $30 \mathrm{~min}$ at RT. Detection of DNA targets was performed with antidigoxigeninfluorescein Fab fragments (Roche Diagnostic) diluted $1: 100$. Washes were performed three times in $4 \times \mathrm{SSC} /$ $0.05 \%$ Tween-20 for 6 min at $42{ }^{\circ} \mathrm{C}$ and three times for 5 min in PBS at RT. Nuclei were counterstained with DAPI in Vectashield mounting medium (Vector Laboratories).

\section{Confocal microscopy and image analysis}

The cells were examined under an LSM 880 confocal microscope with Airyscan (Carl Zeiss). The slides were first examined under a 40×/1.2 Plan-Apochromat objective with visible light and laser excitation line 405 for DAPI in order to detect cells with lipid droplet accumulation (Suppl. Fig. 2) and to identify the cells undergoing adipocyte differentiation. Z-stacks were acquired with a $63 \times / 1.4$ NA Plan-Apochromat oil objective at a step size of $0.2 \mu \mathrm{m}$ and consisted of approximately $35-50$ slices. The pixel size was $71 \mathrm{~nm}$ by $71 \mathrm{~nm}$ by $200 \mathrm{~nm}$. The images were acquired by lasers with three excitation lines: $543 \mathrm{~nm}$ for Cy3 and TRITC, $488 \mathrm{~nm}$ for FITC, and $405 \mathrm{~nm}$ for DAPI. The confocal microscope images were taken with an Airyscan detector in fast scan mode using Zeiss Zen Black software. The pinhole, filters, and objectives were kept at constant settings throughout the examination of all slides. The image stacks were processed by Airyscan processing to increase the signal-tonoise ratio and image resolution. Approximately 200400 nuclei from AD-MSCs and BM-MSCs were analyzed on each of the 7 days of adipogenesis using the TANGO plugin to FIJI (Ollion et al. 2013). The nuclei were segmented from the Z-stacks using a simple segmenter function and the hybridization signals were segmented using a hysteresis segmenter function. The radial position of the hybridization signals was evaluated as described by Kociucka et al. (2012). Briefly, the ratio of the measurement distance was calculated, where $R$ was the distance from the signal to the center of the nucleus divided by the distance from the signal to the nuclear border. A value of $R>4.45$ was taken for the nuclear periphery, $4.45 \geq R \geq 1.37$ was considered an intermediate position, and $R<1.37$ was considered an interior position.
Statistical analysis

Statistical analysis was performed using SAS 9.4 software. All variables were tested for normal distribution. The differences in lipid droplet accumulation were tested using the test for two binomial parameters. The expression levels of PPARG gene and PPAR $\gamma$ protein activity were compared using Student's $t$ test. The differences in gene locations on each day of adipogenesis were tested using multiple comparisons following a Pearson Chi-square test. $P$ values $<0.05$ were considered significant.

\section{Results}

A system of in vitro differentiation of porcine MSC (pMSC) into adipocytes was used to characterize changes in the nuclear positioning of the PPARG locus in relation to its expression. pMSCs were derived from two different sources - adipose tissue (AD-MSC) and bone marrow (BM-MSC). As previously reported by Stachecka et al. (2018), these two cell types have different capacities for differentiation into adipocytes: ADMSCs exhibit greater differentiation potential than BMMSCs, which was evaluated by the accumulation of the amount of lipid droplets (Fig. 1). On day 7 of adipogenic differentiation, $62 \%$ of the cells exhibited visible lipid droplets after Oil Red O staining in AD-MSC, whereas this occurred only in $52 \%$ of BM-MSC cells $(P<0.05$,

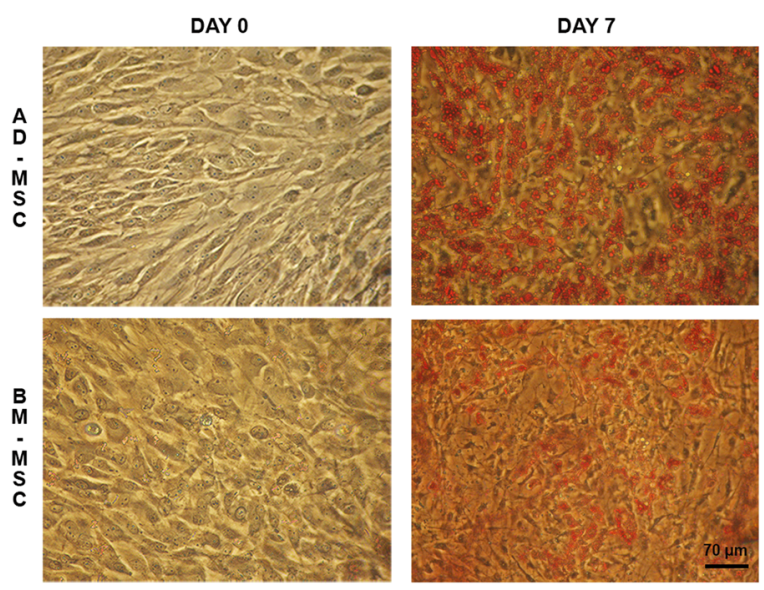

Fig. 1 Adipogenic differentiation of porcine AD-MSCs (top panel) and BM-MSCs (bottom panel). Oil Red O staining was used to visualize lipid droplet formation on days 0 and 7 of adipogenesis. Note the increased accumulation of lipid droplets in AD-MSCs, as compared to BM-MSCs, on day 7 
$n=450$ ). Adipogenesis was carried out for 7 days; on each day, beginning with undifferentiated cells on day 0 , the activity and $3 \mathrm{D}$ location of the PPARG gene were determined.

The PPARG relative transcript level was measured using the AD-MSC and BM-MSC systems. We observed that PPARG was weakly transcribed in both type of undifferentiated cells, and its transcription increased through subsequent days of adipogenesis (Fig. 2a). PPARG transcript was less abundant in BM-MSCs than in AD-MSCs $(P<0.05)$. PPAR $\gamma$ activity was measured as protein binding affinity in the colorimetric assay. It was observed that its activity in the AD-MSC system increased in subsequent days of differentiation, with the highest activity found on day 6 (Fig. $2 b, P<0.05$ ). Surprisingly, no statistically significant differences were found in PPAR $\gamma$ activity during differentiation in BMMSC system. Similarly to the transcript level, the protein activity was also lower in the BM-MSCs than in the
AD-MSCs $(P<0.05)$. These results indicate that the expression of PPARG positively correlates with the adipogenic capacity observed on the cellular level through the formation of mature adipocytes in the ADMSC and BM-MSC.

In the next step, we examined the radial positioning of the PPARG locus relative to the nuclear lamina using 3D DNA/immuno-FISH (Fig. 3a, Suppl. Fig. 3). We observed that, in undifferentiated cells, the gene preferentially occupied the nuclear edge: $79 \%$ of the gene signal in the AD-MSC system and $72 \%$ of the signal in the BM-MSC system had peripheral location (Fig. 3b). The gene was often localized near the nuclear lamina. In subsequent days of adipogenic differentiation, the location of PPARG changed to an intermediate position. On day 3 of differentiation, approximately one third of the $P P A R G$ gene signals showed an intermediate location (39\% of gene signals in AD-MSC and $27 \%$ of gene
Fig. 2 Expression of $P P A R G$ during porcine in vitro adipogenesis. a Relative mRNA levels on subsequent days of differentiation in AD-MSC and BM-MSC systems, calculated for the RPL27 gene and using day 0 as a calibrator (day $0 n_{\mathrm{AD}-\mathrm{MSC}}=$ $16, n_{\mathrm{BM}-\mathrm{MSC}}=16$ ). Error bars show SDs. b PPAR $\gamma$ activity on subsequent days of porcine in vitro adipogenesis $\left(n_{\mathrm{AD}-\mathrm{MSC}}=\right.$ $\left.40, n_{\mathrm{BM}-\mathrm{MSC}}=40\right)$. Error bars show SDs

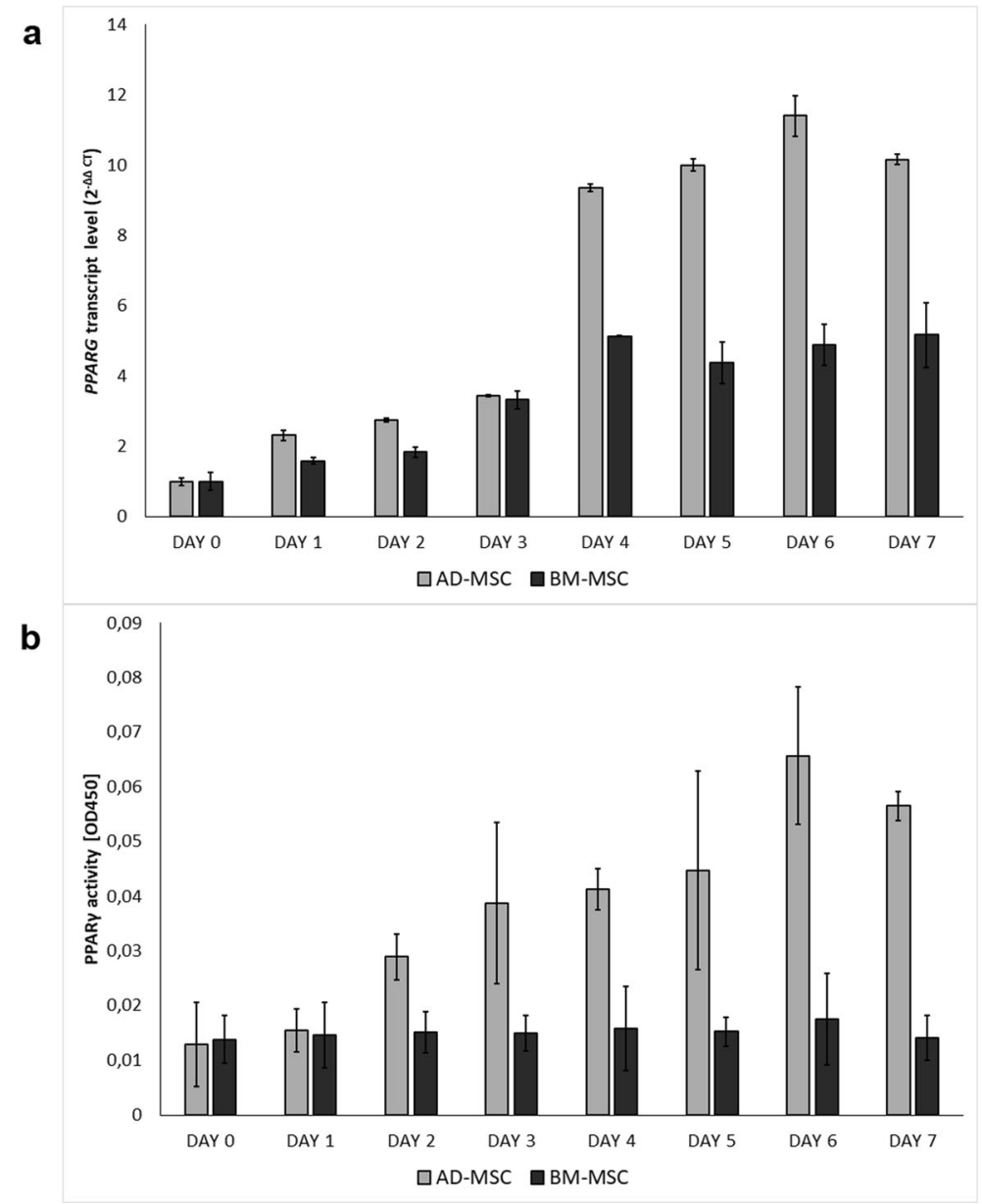




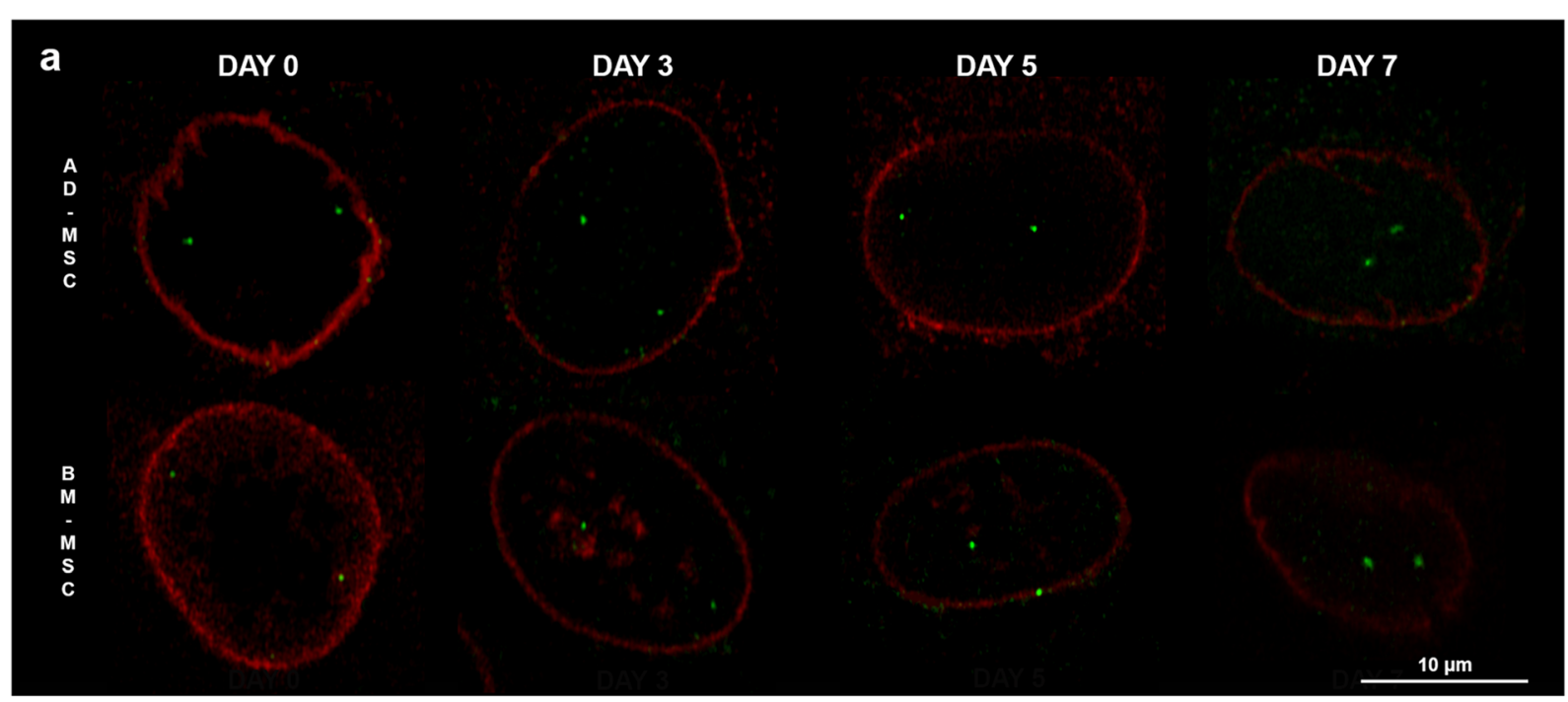

b

LOCATION OF PPARG GENE IN AD-MSC
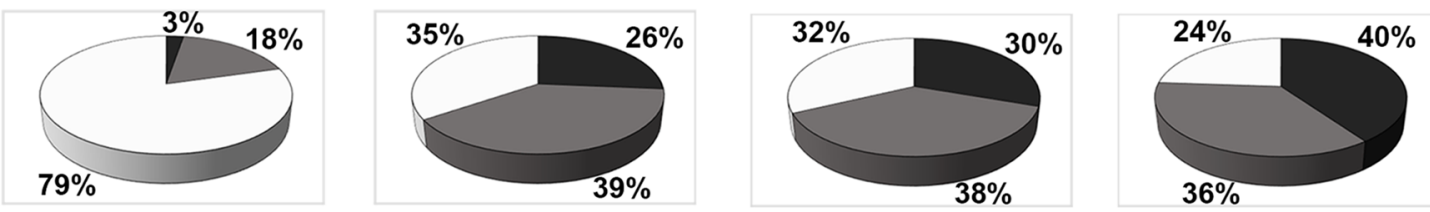

LOCATION OF PPARG GENE IN BM-MSC
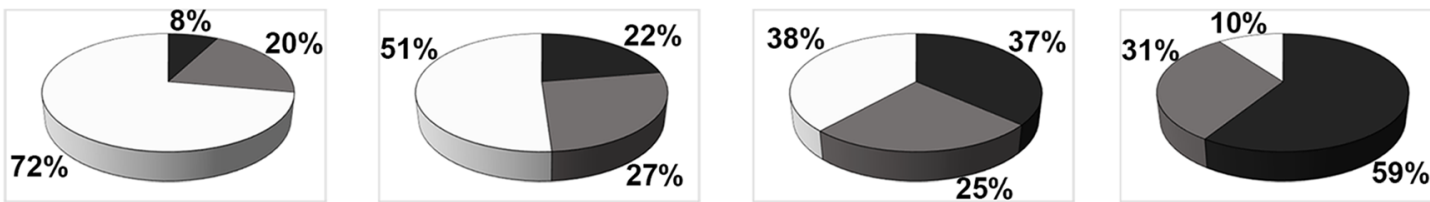

PERIPHERY

INTERMEDIATE $\square$ INTERIOR

Fig. 3 Nuclear positioning of the $P P A R G$ gene during in vitro porcine adipogenesis. a 3D DNA/immuno-FISH was used to visualize the PPARG locus (green) in relation to the nuclear lamina (red). The images are representative confocal slices. Reduced lamin $\mathrm{A} / \mathrm{C}$ expression is characteristic of adipocyte differentiation. b Analysis of the distribution of the PPARG gene in the nuclear

signals in BM-MSC). In the subsequent days of adipogenesis, the percentage of cells with PPARG hybridization signals in the nuclear interior increased. On day 5 , we observed that $30 \%$ of gene signals in $\mathrm{AD}-\mathrm{MSC}$ and $37 \%$ in BM-MSC were in the central part of the cell nucleus; on day 7, this was the case for about $40 \%$ of gene signals in AD-MSC and $59 \%$ in BM-MSC (Fig. 3b). The changes we observed in $P P A R G$ nuclear positioning during the course of adipogenic differentiation in both systems were statistically significant $\left(n_{\mathrm{AD}-\mathrm{MSC}}=469, n_{\mathrm{BM}-\mathrm{MSC}}=405\right.$ $P<0.05$ ) (Suppl. Table 2). space of AD-MSCs and BM-MSCs on days 0, 3, 5, and 7 of adipogenesis. The percentage of hybridization signals located in the nuclear interior, intermediate, and periphery is shown $\left(n_{\mathrm{AD}-}\right.$ MSC $\left.=469, n_{\mathrm{BM}-\mathrm{MSC}}=405, P<0.05\right)$. Note the repositioning of the gene from nuclear periphery to nuclear center during differentiation

We used RNA/DNA-FISH to determine whether changes in the nuclear localization of PPARG are related to its transcriptional status. This technique allowed us to detect primary transcript production from a single allele (Fig. 4a, Suppl. Fig. 4). Alleles positive for the RNA hybridization signal were considered transcriptionally active, while alleles negative for the RNA hybridization signal were considered inactive. On day 0 of differentiation, $72 \%$ of the cells in AD-MSC and $80 \%$ in BMMSC showed no pre-mRNA production from either allele. On subsequent days of adipogenesis, transcription began from a single allele: on day 3,35\% of the 


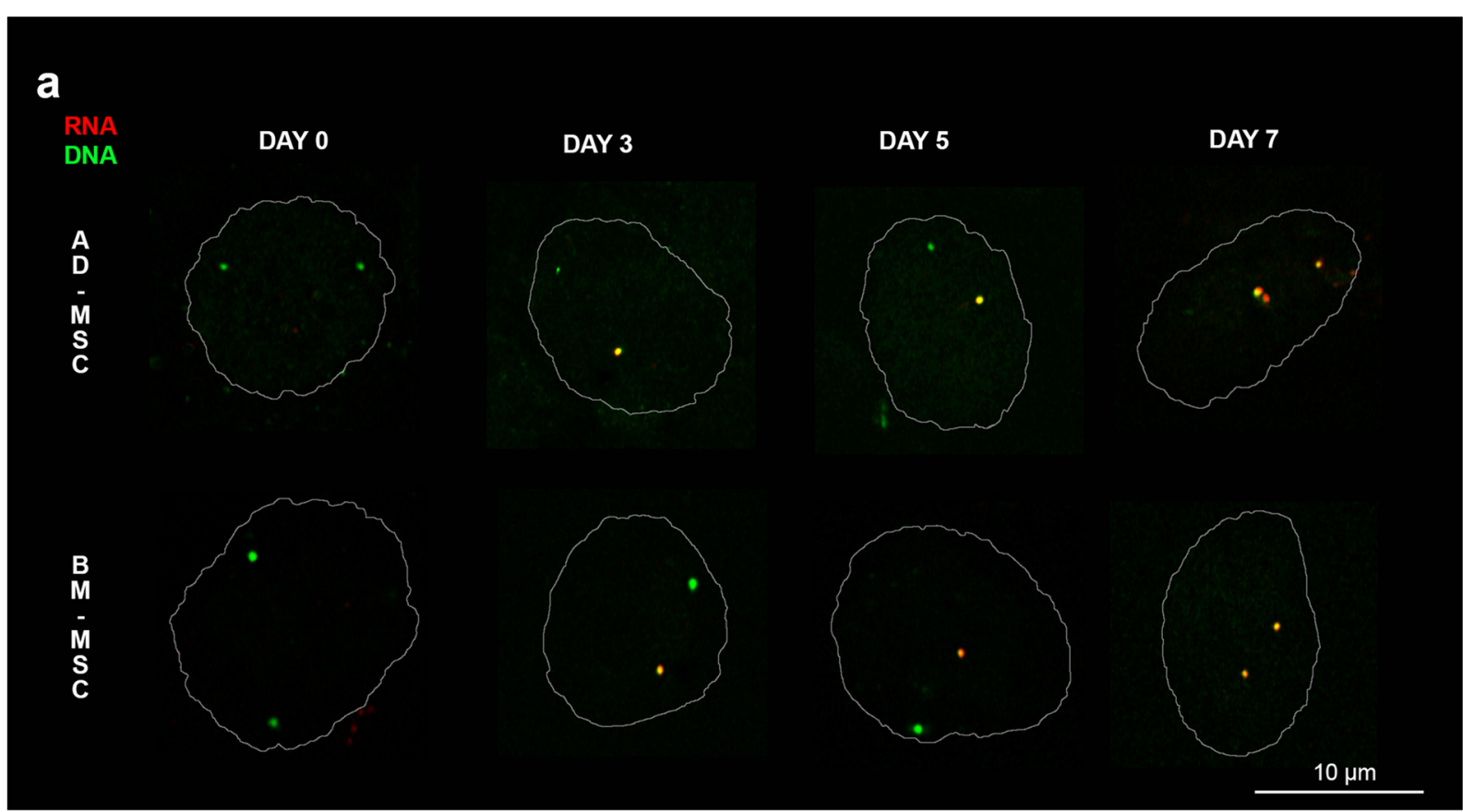

b

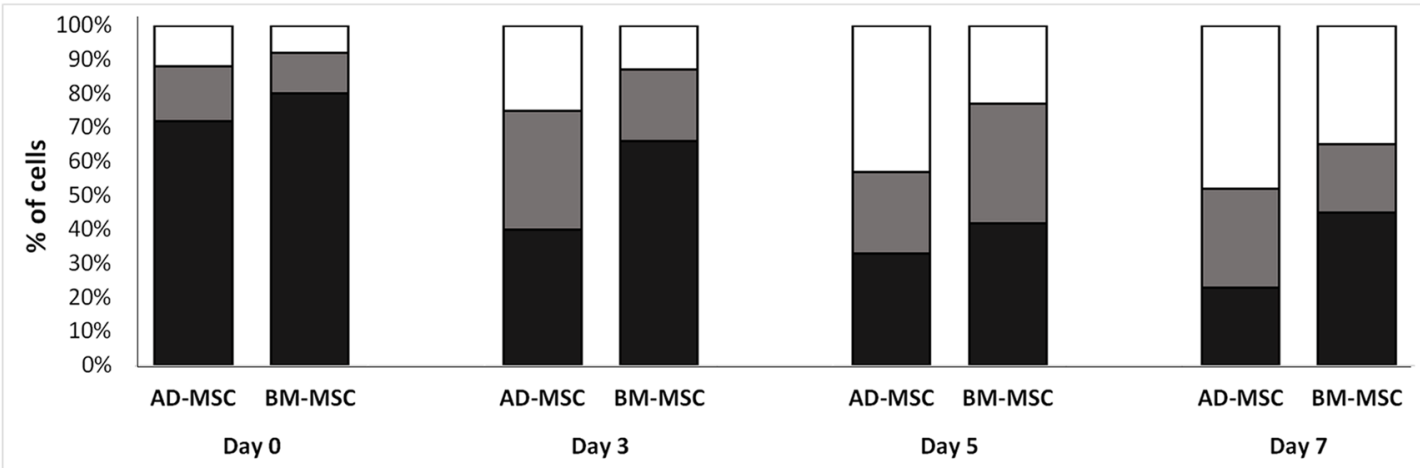

$\square 0 \square 1 \square 2$

Fig. 4 Detection of primary transcript of the $P P A R G$ gene during porcine in vitro adipogenesis. a 3D RNA/DNA-FISH was used to visualize pre-mRNA (red) and DNA locus (green). The limit of nuclear DAPI staining on confocal slices is shown by the white line. b The percentages of cells with 0,1 , or 2 active alleles on

cells in AD-MCS and 21\% in BM-MSC had one active allele. We observed that transcription from both alleles began earlier in AD-MSC than in BM-MSC (43\% of cells versus $23 \%$ ). As differentiation proceeded, both alleles became active: on day 7, 48\% of cells in ADMSC and $35 \%$ in BM-MSC possessed two active alleles (Fig. $4 \mathrm{~b}, n_{\mathrm{AD}-\mathrm{MSC}}=400, n_{\mathrm{BM}-\mathrm{MSC}}=400$ ).

We next examined how the radial position of the $P P A R G$ alleles in nuclear space affects their transcriptional activity. We found that active and inactive alleles had different nuclear positions in the AD-MSC and BM- subsequent days of differentiation $\left(n_{\mathrm{AD}-\mathrm{MSC}}=400, n_{\mathrm{BM}-\mathrm{MSC}}=\right.$ $400, P<0.05)$. Note the preferential location of active alleles in the central part of nucleus and the unequal production of mRNA from both alleles

MSC systems (Fig. 5, Suppl. Table 3). A peripheral location was characteristic of inactive alleles. In undifferentiated cells, $80.6 \%$ of inactive alleles in AD-MSC and $77.4 \%$ in BM-MSC were located on the nuclear periphery. On the other hand, only $7.0 \%$ of active alleles in AD-MSC and $3.6 \%$ in BM-MSC had peripheral locations on day 7. Throughout adipogenic differentiation, as more alleles became active, we observed that they had central and intermediate nuclear positions. By day 7,58.6\% of the active alleles in AD-MSC had central localizations and $34.4 \%$ had intermediate 


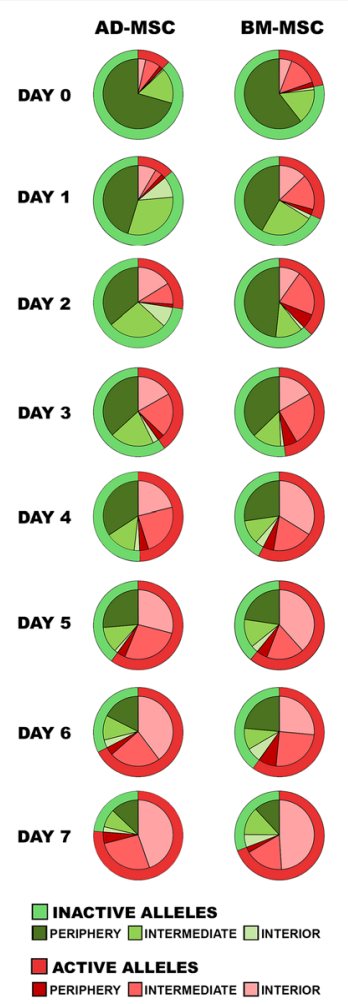

Fig. 5 Distribution of transcriptionally active and inactive alleles of the PPARG gene in the nuclear interior, intermediate, and periphery in the AD-MSC and BM-MSC systems over subsequent days of adipogenic differentiation $\left(n_{\mathrm{AD}-\mathrm{MSC}}=1955, n_{\mathrm{BM}-\mathrm{MSC}}=\right.$ $1461, P<0.05)$

localizations; in BM-MSC, $70.9 \%$ of the active alleles had a central position and $25.5 \%$ were located in intermediate positions. Significant differences in the nuclear location of active and inactive alleles were visible on each day of adipogenic differentiation in both of the examined systems, with active alleles being localized in the central and intermediate nuclear positions, and inactive ones on the nuclear periphery $\left(n_{\mathrm{AD}-\mathrm{MSC}}=1955\right.$, $n_{\mathrm{BM}-\mathrm{MSC}}=1461, P<0.05$, Fig. 5, Suppl. Table 3). We also compared the nuclear position of active and inactive alleles in all the examined cells with only one transcriptionally active allele. We observed that active alleles preferentially occupied central and intermediate positions. In AD-MSC, $44.8 \%$ of active alleles had central positions and $48.5 \%$ had intermediate positions, while in BM-MSC, $44.3 \%$ of active alleles had central positions and $46.9 \%$ had intermediate positions. Inactive alleles were located preferentially on the nuclear periphery $(58.7 \%$ in AD-MSC and $61.1 \%$ in BM-MSC) (Supp. Fig. 5, Suppl. Table 4). Our results indicate that there is a relationship between $P P A R G$ gene activity and its nuclear positioning.

\section{Discussion}

In this study, we have described the detailed behavior of the locus of the PPARG gene in the nuclear space on each of the 7 days of differentiation of porcine mesenchymal stem cells into adipocytes. The gene was upregulated during differentiation. Its transcript level was higher in AD-MSC than in BM-MSC, which can be explained by the different adipogenic potential of these two types of MSCs. We have shown that higher expression of the PPARG gene enhances adipogenesis in ADMSC. Similar results to those in this study have also been reported in humans (Liu et al. 2017); the authors of that report examined the adipogenic ability of MSCs isolated from umbilical cords, adipose tissue, and bone marrow and found AD-MSCs to display the highest potential to undergo adipogenesis - which could be an effect of the different expression pattern of the miR$301 \mathrm{~b} \sim \mathrm{miR}-130 \mathrm{~b}-\mathrm{PPAR} \gamma$ axis. Also, overexpression of the $P P A R G$ gene enhanced and accelerated the adipogenic differentiation of hemangioma-derived mesenchymal stem cells (Hem-MSCs) (Yuan et al. 2017). Correlation between the PPARG gene's transcriptional and protein activity was observed only in the AD-MSC system. That lack of difference in the activity of $P P A R G$ on subsequent days of adipogenesis in BM-MC can be explained by the small amount of PPAR $\gamma$ in the nuclear extract of these cell types, and the limitations involved in detecting it using immunoassays, as has been previously reported by Chan and Cipolla (2012).

The repositioning of the PPARG gene from the nuclear periphery to the nuclear center corresponded with its transcriptional activity. This is in agreement with observations in a previous study, where only three time points (days 0,7 , and 14 of adipogenesis) were evaluated by RT-PCR (Szczerbal et al. 2009). Here, using more advanced techniques, we compared two different systems of adipogenic differentiation (AD-MSC and BM-MSC) and detected gradual changes in PPARG repositioning and transcript level on each day of adipogenesis. Along with the progression of adipogenesis, the number of cells with a centrally located gene locus significantly increased. This indicates that changes in PPARG nuclear relocation are a universal phenomenon, 
independent of the experiment and of the types of cell used as progenitors.

The nuclear periphery is generally considered to be a transcriptionally less active part of the cell nucleus. Genomic regions in contact with the nuclear lamina, termed lamina-associated domains (LADs), have been linked to gene repression (van Steensel and Belmont 2017). Two classes of LAD have been distinguished: constitutive LADs that interact with the lamina in all cell types, and facultative LADs, which are cell-type specific (Meuleman et al. 2013). A number of repositioning events from the nuclear periphery to the nuclear interior have been described, mainly during the processes of differentiation and development, including erythropoiesis, lymphopoiesis, and neuronal differentiation (Kosak et al. 2002; Kim et al. 2004; Ragoczy et al. 2006; Williams et al. 2006; Peric-Hupkes et al. 2010). Other cellular processes, such as senescence, have been shown to be characterized by massive changes in LAD organization (Lenain et al. 2017). Our previous study also showed that adipogenesis is characterized by a reorganization of nuclear lamina (Stachecka et al. 2018). The experimental targeting of genes to the nuclear periphery has also been shown to result in transcriptional repression (Finlan et al. 2008; Reddy et al. 2008); however, not all genes were subjected to these mechanisms (Kumaran and Spector 2008). It has been also demonstrated that the relocation of genes from the nuclear envelope to the nuclear interior during differentiation is driven by chromatin remodeling, rather than by transcription per se (Therizols et al. 2014). Analysis of the genome-wide chromatin state in two models of adipogenesis (murine and human) has shown that one of the promoters (P2) of the PPARG gene dissociates from the lamina and acquires $\mathrm{H} 3 \mathrm{~K} 4 \mathrm{me} 3$ modification as it is upregulated in adipocytes (Mikkelsen et al. 2010; Lund and Collas 2013). Unfortunately, such analysis was not performed so far for the porcine PPARG gene. A study of the nuclear arrangement of other genes important in lipid metabolism in porcine adipocytes in fat tissue showed that the correlation between transcription level and 3D location existed only for some genes (Kociucka et al. 2012). In addition, the transcriptional activation of genes by hormone addition or bacterial infection did not induce changes in the positioning of genes in the nuclear space (Kocanova et al. 2010; Hakim et al. 2011; Solinhac et al. 2011). There are also examples of genes in cancer cells that have been found to alter their nuclear position without changes in expression (Meaburn and Misteli 2008). This indicates that the relationship between the radial positioning of genes and their transcriptional status is complex. Our study has confirmed previous suggestions that nuclear repositioning is mainly typical of genes that switch from the silent state to the active state during differentiation processes (Joffe et al. 2010).

We have here demonstrated the allele-specific radial nuclear positioning of PPARG during in vitro adipogenesis. In mature adipocytes, the active alleles preferentially occupied the interior of the nucleus. On day 7 of differentiation, only 3.6-7.0\% of active alleles were located on the nuclear periphery. Different positioning of the alleles in nuclear space was also reported by Takizawa et al. (2008), who studied the monoallelically expressed GFAP gene and showed that the active allele was more internally localized than the nonexpressed allele. Genes that undergo random autosomal monoallelic expression are good models for studying the link between nuclear architecture and gene expression. It has been shown that nuclear positioning is important for the monoallelic expression of immunoglobulin (Skok et al. 2001) and olfactory receptor (Clowney et al. 2012) genes, but this has not been demonstrated for monoallelic expressed genes in mouse embryonic stem cells or neural progenitor cells (Eckersley-Maslin et al. 2014), as the researcher did not find a preferential location of inactive alleles at the nuclear periphery or near heterochromatic foci.

The PPARG gene undergoes biallelic expression. Analysis of the allele-specific expression of this gene in porcine fat tissues has shown that both alleles are expressed at similar levels (Stachowiak et al. 2018). However, the use of RNA/DNA-FISH allowed us to detect temporal differences in PPARG transcript production. In spite of the biallelic nature of $P P A R G$ gene expression, the transcript is initially produced from only one allele. Such subtle differences in transcript production and accumulation could easily be detected with microscopic techniques. It is well established that FISH-based methods have many advantages in studies of nuclear architecture - for example, RNA-FISH allows the detection of the spatial and temporal organization of gene transcription in individual cells and the identification of intercellular variation. However, a limitation of such techniques is their low throughput; thus, they are usually used only to analyze candidate genes (Meaburn 2016; Brown and Buckle 2010). 
The spatial positioning of genomic loci can be also studied with biochemical methods originating from the chromatin conformation capture technique (3C), such as 3C, 4C, 5C, and Hi-C (Dekker and Misteli 2015). These approaches have also been used to study the PPARG gene. It has been shown that, during the differentiation of mouse 3T3-L1 and C3H10T1/2 cell lines into adipocytes, the PPARG locus makes long-range chromatin interactions with selected tissue-specific loci, encoding adipokines and lipid-droplet-associated proteins, such as perlipin, adiponectin, and leptin (LeBlanc et al. 2014), or creating an adipogenic-specific nuclear subcompartment referred as a "hub" with the Lpin1 gene (Sarusi Portuguez et al. 2017). To date, chromatin interaction studies on a genome-wide level have not been performed for porcine adipogenesis. However, it can be anticipated that the observed repositioning of the $P P A R G$ gene is associated with its interaction with other chromosomal regions or nuclear subcompartments, as has been previously observed in the case of SC-35 domains (Szczerbal and Bridger 2010).

There is no doubt that the position of genes in nuclear space is not random. However, it is still not clear whether gene repositioning events are necessary for activation or are merely a consequence of the gene expression program (Shachar and Misteli 2017). The molecular mechanisms governing the spatial reposition of genes have not yet been fully elucidated. However, based on the results obtained so far, it seems that these mechanisms may differ for different loci and may depend on nuclear envelope proteins (Solovei et al. 2013), DNA sequence (Zullo et al. 2012), histone modifications (Towbin et al. 2012), and replication (Shachar et al. 2015). It can be anticipated that the use of new technologies, such as single-cell $\mathrm{Hi}-\mathrm{C}$ and CRISPR-Cas9 methods (Ramani et al. 2017; Morgan et al. 2017), will lead to deeper insights into the mechanisms that determine the spatial positions of genes and their functional consequence. Understanding how nuclear architecture contributes to the expression of adipogenic genes and the establishment of mature adipocytes is important for both biomedical and animal sciences.

\footnotetext{
Authors' contribution JS carried out all experiments, analyzed the data, and contributed to drafting the manuscript. JNW and PK performed experiments and contributed to the data analysis. IS developed the research design and supervised the study, contributed to the experimental analysis and interpretation of the data, and was responsible for manuscript preparation and submission. All authors read and approved the final manuscript.
}

Funding information This work was supported by the National Science Centre in Poland, grant no. 2012/07/E/NZ9/02573.

\section{Compliance with ethical standards}

Ethical approval The collection of tissue samples was approved by the Local Ethical Commission on Experiments on Animals at Poznan University of Life Sciences, Poznan, Poland (approval No. 57/2012).

Conflict of interest The authors declare that they have no conflicts of interest.

Open Access This article is distributed under the terms of the Creative Commons Attribution 4.0 International License (http:// creativecommons.org/licenses/by/4.0/), which permits unrestricted use, distribution, and reproduction in any medium, provided you give appropriate credit to the original author(s) and the source, provide a link to the Creative Commons license, and indicate if changes were made.

Publisher's note Springer Nature remains neutral with regard to jurisdictional claims in published maps and institutional affiliations.

\section{References}

Anderson SI, Lopez-Corrales NL, Gorick B, Archibald AL (2000) A large-fragment porcine genomic library resource in a BAC vector. Mamm Genome 11(9):811-814

Bolzer A, Kreth G, Solovei I, Koehler D, Saracoglu K, Fauth C, Müller S, Eils R, Cremer C, Speicher MR, Cremer T (2005) Three-dimensional maps of all chromosomes in human male fibroblast nuclei and prometaphase rosettes. PLoS Biol 3: e157. https://doi.org/10.1371/journal.pbio.0030157

Brown JM, Buckle VJ (2010) Detection of nascent RNA transcripts by fluorescence in situ hybridization. Methods Mol Biol 659: 33-50. https://doi.org/10.1007/978-1-60761-789-1 3

Chan SL, Cipolla MJ (2012) Determination of PPAR $\gamma$ activity in adipose tissue and spleen. J Immunoassay Immunochem 33: 314-324. https://doi.org/10.1080/15321819.2011.647189

Charó NL, Rodríguez Ceschan MI, Galigniana NM, Toneatto J, Piwien-Pilipuk G (2016) Organization of nuclear architecture during adipocyte differentiation. Nucleus 7:249-269. https://doi.org/10.1080/19491034.2016.1197442

Clowney EJ, LeGros MA, Mosley CP, Clowney FG, Markenskoff-Papadimitriou EC, Myllys M, Barnea G, Larabell CA, Lomvardas S (2012) Nuclear aggregation of olfactory receptor genes governs their monogenic expression. Cell 151:724-737. https://doi.org/10.1016/j.cell.2012.09.043

Cremer T, Cremer M (2010) Chromosome territories. Cold Spring Harb Perspect Biol 2:a003889. https://doi.org/10.1101 /cshperspect.a003889

Dekker J, Misteli T (2015) Long-range chromatin interactions. Cold Spring Harb Perspect Biol 7:a019356. https://doi. org/10.1101/cshperspect.a019356 
Dixon JR, Selvaraj S, Yue F, Kim A, Li Y, Shen Y, Hu M, Liu JS, Ren B (2012) Topological domains in mammalian genomes identified by analysis of chromatin interactions. Nature 485 : 376-380. https://doi.org/10.1038/nature11082

Eckersley-Maslin MA, Thybert D, Bergmann JH, Marioni JC, Flicek P, Spector DL (2014) Random monoallelic gene expression increases upon embryonic stem cell differentiation. Dev Cell 28:351-365. https://doi.org/10.1016/j. devcel.2014.01.017

Farmer SR (2006) Transcriptional control of adipocyte formation. Cell Metab 4:263-273. https://doi.org/10.1016/j. cmet.2006.07.001

Fedorova E, Zink D (2008) Nuclear architecture and gene regulation. Biochim Biophys Acta 1783:2174-2184. https://doi. org/10.1016/j.bbamcr.2008.07.018

Ferrai C, de Castro IJ, Lavitas L, Chotalia M, Pombo A (2010) Gene positioning. Cold Spring Harb Perspect Biol 2: a000588. https://doi.org/10.1101/cshperspect.a000588

Finlan LE, Sproul D, Thomson I, Boyle S, Kerr E, Perry P, Ylstra B, Chubb JR, Bickmore WA (2008) Recruitment to the nuclear periphery can alter expression of genes in human cells. PLoS Genet 4:e1000039. https://doi.org/10.1371 /journal.pgen.1000039

Fraser P, Bickmore W (2007) Nuclear organization of the genome and the potential for gene regulation. Nature 447:413-417. https://doi.org/10.1038/nature05916

Fujiki K, Kano F, Shiota K, Murata M (2009) Expression of the peroxisome proliferator activated receptor gamma gene is repressed by DNA methylation in visceral adipose tissue of mouse models of diabetes. BMC Biol 7:38. https://doi. org/10.1186/1741-7007-7-38

Hakim O, Sung MH, Voss TC, Splinter E, John S, Sabo PJ, Thurman RE, Stamatoyannopoulos JA, de Laat W, Hager GL (2011) Diverse gene reprogramming events occur in the same spatial clusters of distal regulatory elements. Genome Res 21:697-706. https://doi.org/10.1101/gr.111153.110

Joffe B, Leonhardt H, Solovei I (2010) Differentiation and large scale spatial organization of the genome. Curr Opin Genet Dev 20:562-569. https://doi.org/10.1016/j.gde.2010.05.009

Kim SH, McQueen PG, Lichtman MK, Shevach EM, Parada LA, Misteli T (2004) Spatial genome organization during T-cell differentiation. Cytogenet Genome Res 105:292-301. https://doi.org/10.1159/000078201

Kocanova S, Kerr EA, Rafique S, Boyle S, Katz E, Caze-Subra S, Bickmore WA, Bystricky K (2010) Activation of estrogenresponsive genes does not require their nuclear co-localization. PLoS Genet 6:e1000922. https://doi.org/10.1371 /journal.pgen.1000922

Kociucka B, Cieslak J, Szczerbal I (2012) Three-dimensional arrangement of genes involved in lipid metabolism in nuclei of porcine adipocytes and fibroblasts in relation to their transcription level. Cytogenet Genome Res 136:295-302. https://doi.org/10.1159/000338255

Kociucka B, Flisikowska T, Mroz D, Szczerbal I (2016) Expression of genes involved in lipid droplet formation (BSCL2, SNAP23 and COPA) during porcine in vitro adipogenesis. J Appl Genet 57:505-510. https://doi.org/10.1007 /s13353-016-0350-9

Kosak ST, Skok JA, Medina KL, Riblet R, Le Beau MM, Fisher AG, Singh H (2002) Subnuclear compartmentalization of immunoglobulin loci during lymphocyte development.
Science 296:158-162. https://doi.org/10.1126 /science. 1068768

Kumaran RI, Spector DL (2008) A genetic locus targeted to the nuclear periphery in living cells maintains its transcriptional competence. J Cell Biol 180:51-65. https://doi.org/10.1083 /jcb.200706060

LeBlanc SE, Wu Q, Barutcu AR, Xiao H, Ohkawa Y, Imbalzano AN (2014) The PPAR $\gamma$ locus makes long-range chromatin interactions with selected tissue-specific gene loci during adipocyte differentiation in a protein kinase a dependent manner. PLoS One 9:e86140. https://doi.org/10.1371 /journal.pone.0086140

Lee JE, Ge K (2014) Transcriptional and epigenetic regulation of PPAR $\gamma$ expression during adipogenesis. Cell Biosci 4:29. https://doi.org/10.1186/2045-3701-4-29

Lehrke M, Lazar MA (2005) The many faces of PPARgamma. Cell 123:993-999. https://doi.org/10.1016/j.cell.2005.11.026

Lenain C, de Graaf CA, Pagie L, Visser NL, de Haas M, de Vries SS, Peric-Hupkes D, van Steensel B, Peeper DS (2017) Massive reshaping of genome-nuclear lamina interactions during oncogene-induced senescence. Genome Res 27: 1634-1644. https://doi.org/10.1101/gr.225763.117

Lieberman-Aiden E, van Berkum NL, Williams L, Imakaev M, Ragoczy T, Telling A, Amit I, Lajoie BR, Sabo PJ, Dorschner MO, Sandstrom R, Bernstein B, Bender MA, Groudine M, Gnirke A, Stamatoyannopoulos J, Mirny LA, Lander ES, Dekker J (2009) Comprehensive mapping of long-range interactions reveals folding principles of the human genome. Science 326:289-293. https://doi.org/10.1126 /science. 1181369

Liu L, Liu H, Chen M, Ren S, Cheng P, Zhang H (2017) miR301b miR-130b-PPAR $\gamma$ axis underlies the adipogenic capacity of mesenchymal stem cells with different tissue origins. Sci Rep 7(1160):1160. https://doi.org/10.1038/s41598017-01294-2

Livak KJ, Schmittgen TD (2001) Analysis of relative gene expression data using real-time quantitative PCR and the $2-\Delta \Delta \mathrm{CT}$ method. Methods 25:402-408. https://doi.org/10.1006 /meth.2001.1262

Louveau I, Perruchot MH, Bonnet M, Gondret F (2016) Invited review: pre- and postnatal adipose tissue development in farm animals: from stem cells to adipocyte physiology. Animal 10:1839-1847. https://doi.org/10.1017 /S1751731116000872

Lowe CE, O'Rahilly S, Rochford JJ (2011) Adipogenesis at a glance. J Cell Sci 124:2681-2686. https://doi.org/10.1242 /jcs.079699

Lund E, Collas P (2013) Nuclear lamins: making contacts with promoters. Nucleus 4:424-430. https://doi.org/10.4161 /nucl.26865

Meaburn KJ (2016) Spatial genome organization and its emerging role as a potential diagnosis tool. Front Genet 7:134. https://doi.org/10.3389/fgene.2016.00134

Meaburn KJ, Misteli T (2008) Locus-specific and activity- independent gene repositioning during early tumorigenesis. J Cell Biol 180:39-50. https://doi.org/10.1083/jcb.200708204

Meister P, Towbin BD, Pike BL, Ponti A, Gasser SM (2010) The spatial dynamics of tissue-specific promoters during $\mathrm{C}$. Elegans development. Genes Dev 24:766-782. https://doi. org $/ 10.1101 / \mathrm{gad} .559610$ 
Meuleman W, Peric-Hupkes D, Kind J, Beaudry JB, Pagie L, Kellis M, Reinders M, Wessels L, van Steensel B (2013) Constitutive nuclear lamina-genome interactions are highly conserved and associated with a/T-rich sequence. Genome Res 23:270-280. https://doi.org/10.1101/gr.141028.112

Mikkelsen TS, Xu Z, Zhang X, Wang L, Gimble JM, Lander ES, Rosen ED (2010) Comparative epigenomic analysis of murine and human adipogenesis. Cell 143:156-169. https://doi. org/10.1016/j.cell.2010.09.006

Morgan SL, Mariano NC, Bermudez A, Arruda NL, Wu F, Luo Y, Shankar G, Jia L, Chen H, Hu JF, Hoffman AR, Huang CC, Pitteri SJ, Wang KC (2017) Manipulation of nuclear architecture through CRISPR-mediated chromosomal looping. Nat Commun 8:15993. https://doi.org/10.1038 /ncomms 15993

Mota de Sá P, Richard AJ, Hang H, Stephens JM (2017) Transcriptional regulation of Adipogenesis. Compr Physiol 7:635-674. https://doi.org/10.1002/cphy.c160022

Ollion J, Cochennec J, Loll F, Escudé C, Boudier T (2013) TANGO: a generic tool for high-throughput 3D image analysis for studying nuclear organization. Bioinformatics 29: 1840-1841. https://doi.org/10.1093/bioinformatics/btt276

Peric-Hupkes D, Meuleman W, Pagie L, Bruggeman SWM, Solovei I, Brugman W, Gräf S, Flicek P, Kerkhoven RM, van Lohuizen M, Reinders M, Wessels L, van Steensel B (2010) Molecular maps of the reorganization of genomenuclear Lamina interactions during differentiation. Mol Cell 38:603-613. https://doi.org/10.1016/j.molcel.2010.03.016

Phillips-Cremins JE, Sauria ME, Sanyal A, Gerasimova TI, Lajoie BR, Bell JS, Ong CT, Hookway TA, Guo C, Sun Y, Bland MJ, Wagstaff W, Dalton S, McDevitt TC, Sen R, Dekker J, Taylor J, Corces VG (2013) Architectural protein subclasses shape 3D organization of genomes during lineage commitment. Cell 153:1281-1295. https://doi.org/10.1016/j. cell.2013.04.053

Ragoczy T, Bender MA, Telling A, Byron R, Groudine M (2006) The locus control region is required for association of the murine beta-globin locus with engaged transcription factories during erythroid maturation. Genes Dev 20:1447-1457. https://doi.org/10.1101/gad.1419506

Ramani V, Deng X, Qiu R, Gunderson KL, Steemers FJ, Disteche CM, Noble WS, Duan Z, Shendure J (2017) Massively multiplex single-cell hi-C. Nat Methods 14:263-266. https://doi.org/10.1038/nmeth.4155

Rao SS, Huntley MH, Durand NC, Stamenova EK, Bochkov ID, Robinson JT, Sanborn AL, Machol I, Omer AD, Lander ES, Aiden EL (2014) A 3D map of the human genome at kilobase resolution reveals principles of chromatin looping. Cell 159: 1665-1680. https://doi.org/10.1016/j.cell.2014.11.021

Reddy KL, Zullo JM, Bertolino E, Singh H (2008) Transcriptional repression mediated by repositioning of genes to the nuclear lamina. Nature 452:243-247. https://doi.org/10.1038 /nature 06727

Rosen ED, MacDougald OA (2006) Adipocyte differentiation from the inside out. Nat Rev Mol Cell Biol 7:885-896. https://doi.org/10.1038/nrm2066

Ruschke K, Fishbein L, Dietrich A, Klöting N, Tönjes A, Oberbach A, Fasshauer M, Jenkner J, Schön MR, Stumvoll M, Blüher M, Mantzoros CS (2010) Gene expression of PPARgamma and PGC-1alpha in human omental and subcutaneous adipose tissues is related to insulin resistance markers and mediates beneficial effects of physical training. Eur J Endocrinol 162:515-523. https://doi.org/10.1530/EJE09-0767

Sanborn AL, Rao SS, Huang SC, Durand NC, Huntley MH, Jewett AI, Bochkov ID, Chinnappan D, Cutkosky A, Li J, Geeting KP, Gnirke A, Melnikov A, McKenna D, Stamenova EK, Lander ES, Aiden EL (2015) Chromatin extrusion explains key features of loop and domain formation in wildtype and engineered genomes. Proc Natl Acad Sci U S A 112: E6456-E6465. https://doi.org/10.1073/pnas.1518552112

Sarusi Portuguez A, Schwartz M, Siersbaek R, Nielsen R, Sung MH, Mandrup S, Kaplan T, Hakim O (2017) Hierarchical role for transcription factors and chromatin structure in genome organization along adipogenesis. FEBS J 284:32303244. https://doi.org/10.1111/febs. 14183

Shachar S, Misteli T (2017) Causes and consequences of nuclear gene positioning. J Cell Sci 130:1501-1508. https://doi. org/10.1242/jcs. 199786

Shachar S, Voss TC, Pegoraro G, Sciascia N, Misteli T (2015) Identification of gene positioning factors using highthroughput imaging mapping. Cell 162:911-923. https://doi.org/10.1016/j.cell.2015.07.035

Shao X, Wang M, Wei X, Deng S, Fu N, Peng Q, Jiang Y, Ye L, Xie J, Lin Y (2016) Peroxisome proliferator-activated receptor- $\gamma$ : master regulator of Adipogenesis and obesity. Curr Stem Cell Res Ther 11:282-289

Siersbæk R, Nielsen R, Mandrup S (2010) PPARgamma in adipocyte differentiation and metabolism-novel insights from genome-wide studies. FEBS Lett 584:3242-3249. https://doi.org/10.1016/j.febslet.2010.06.010

Skok JA, Brown KE, Azuara V, Caparros ML, Baxter J, Takacs K, Dillon N, Gray D, Perry RP, Merkenschlager M, Fisher AG (2001) Nonequivalent nuclear location of immunoglobulin alleles in B lymphocytes. Nat Immunol 2:848-854. https://doi.org/10.1038/ni0901-848

Solinhac R, Mompart F, Martin P, Robelin D, Pinton P, Iannuccelli E, Lahbib-Mansais Y, Oswald IP, Yerle-Bouissou M (2011) Transcriptomic and nuclear architecture of immune cells after LPS activation. Chromosoma 120:501-520. https://doi. org/10.1007/s00412-011-0328-7

Solovei I, Cremer M (2010) 3D-FISH on cultured cells combined with immunostaining. Methods Mol Biol 659:117-126. https://doi.org/10.1007/978-1-60761-789-1_8

Solovei I, Wang AS, Thanisch K, Schmidt CS, Krebs S, Zwerger M, Cohen TV, Devys D, Foisner R, Peichl L, Herrmann H, Blum H, Engelkamp D, Stewart CL, Leonhardt H, Joffe B (2013) LBR and Lamin a/C sequentially tether peripheral heterochromatin and inversely regulate differentiation. Cell 152:584-598. https://doi.org/10.1016/j.cell.2013.01.009

Stachecka J, Walczak A, Kociucka B, Ruszczycki B, Wilczyński G, Szczerbal I (2018) Nuclear organization during in vitro differentiation of porcine mesenchymal stem cells (MSCs) into adipocytes. Histochem Cell Biol 149:113-126. https://doi.org/10.1007/s00418-017-1618-9

Stachowiak M, Szczerbal I, Switonski M (2016) Genetics of adiposity in large animal models for human obesity-studies on pigs and dogs. Prog Mol Biol Transl Sci 140:233-270. https://doi.org/10.1016/bs.pmbts.2016.01.001

Stachowiak M, Szczerbal I, Flisikowski K (2018) Investigation of allele-specific expression of genes involved in adipogenesis and lipid metabolism suggests complex regulatory 
mechanisms of PPARGC1A expression in porcine fat tissues. BMC Genet 19(107):107. https://doi.org/10.1186/s12863018-0696-6

van Steensel B, Belmont AS (2017) Lamina-associated domains: links with chromosome architecture, heterochromatin, and gene repression. Cell 169:780-791. https://doi.org/10.1016 j.cell.2017.04.022

Sugii S, Evans RM (2011) Epigenetic codes of PPAR $\gamma$ in metabolic disease. FEBS Lett 585:2121-2128. https://doi. org/10.1016/j.febslet.2011.05.007

Szczerbal I, Bridger JM (2010) Association of adipogenic genes with SC-35 domains during porcine adipogenesis. Chromosom Res 18:887-895. https://doi.org/10.1007 /s10577-010-9176-1

Szczerbal I, Foster HA, Bridger JM (2009) The spatial repositioning of adipogenesis genes is correlated with their expression status in a porcine mesenchymal stem cell adipogenesis model system. Chromosoma 118:647-663. https://doi. org/10.1007/s00412-009-0225-5

Takizawa T, Gudla PR, Guo L, Lockett S, Misteli T (2008) Allelespecific nuclear positioning of the monoallelically expressed astrocyte marker GFAP. Genes Dev 22:489-498. https://doi. org/10.1101/gad.1634608

Therizols P, Illingworth RS, Courilleau C, Boyle S, Wood AJ, Bickmore WA (2014) Chromatin decondensation is sufficient to alter nuclear organization in embryonic stem cells. Science 346:1238-1242. https://doi.org/10.1126/science.1259587

Towbin BD, González-Aguilera C, Sack R, Gaidatzis D, Kalck V, Meister P, Askjaer P, Gasser SM (2012) Step-wise methylation of histone $\mathrm{H} 3 \mathrm{~K} 9$ positions heterochromatin at the nuclear periphery. Cell 150:934-947. https://doi.org/10.1016/j. cell.2012.06.051

Williams RR, Azuara V, Perry P, Sauer S, Dvorkina M, Jørgensen H, Roix J, McQueen P, Misteli T, Merkenschlager M, Fisher AG (2006) Neural induction promotes large-scale chromatin reorganisation of the Mash1 locus. J Cell Sci 119:132-140. https://doi.org/10.1242/jcs.02727

Yuan SM, Guo Y, Wang Q, Xu Y, Wang M, Chen HN, Shen WM (2017) Over-expression of PPAR- $\gamma 2$ gene enhances the adipogenic differentiation of hemangioma-derived mesenchymal stem cells in vitro and in vivo. Oncotarget 8: 115817-115828. https://doi.org/10.18632/oncotarget.23705

Zullo JM, Demarco IA, Piqué-Regi R, Gaffney DJ, Epstein CB, Spooner CJ, Luperchio TR, Bernstein BE, Pritchard JK, Reddy KL, Singh H (2012) DNA sequence-dependent compartmentalization and silencing of chromatin at the nuclear lamina. Cell 149:1474-1487. https://doi.org/10.1016/j. cell.2012.04.035 